\begin{tabular}{lc}
\hline J-PAI: Jurnal Pendidikan Agama Islam & p-ISSN 2355-8237 \\
Vol. 5 No. 2 Januari-Juni 2019 & e-ISSN 2503-300X \\
\hline
\end{tabular}

\title{
PENERAPAN MODEL PEMBELAJARAN SCRAMBLE BERBASIS POWERPOINT UNTUK MENINGKATKAN HASIL BELAJAR SISWA PADA BIDANG STUDI SEJARAH KEBUDAYAAN ISLAM
}

\author{
Dini Fitria*, Johan Andriesgo** \\ Universitas Islam Kuantan Singingi, Riau, Indonesia \\ Email:*dinifitria@gmail.com,**Johanandriesgo@gmail.com
}

\begin{abstract}
This study aimed to determine the application of powerpoint-based scramble learning models in improving student learning outcomes in the field of study of the History of Islamic Culture Class VII One in Madrasah Tsanawiyah PP. Nurul Islam Kampung Baru. This research is a classroom action research, namely research that is practical, situational and contextual based on the problems that arise in learning activities in the field of study of the History of Islamic Culture in Madrasah Tsanawiyah PP. Nurul Islam Kampung Baru. Based on the research conducted, it can be concluded that the implementation of learning the History of Islamic Culture by applying the powerpoint-based scramble learning model is carried out by steps namely: pre-learning, initial activities, core activities, and concluding. After applying the powerpoint-based scramble learning model in class VII One in Madrasah Tsanawiyah PP. Nurul Islam Kampung Baru shows there is an increase in student learning outcomes. This can be seen from, before the action of the class average reached 71.30 and only 9 students or $39.13 \%$ who achieved mastery learning, but in the first cycle, using the power point scramble learning model increased with an average the class reached 76.39 and there were 15 students or $65.22 \%$ who achieved mastery learning, and the increase continued in the second cycle with the class average reaching 85.74 and 22 students or $95.65 \%$ who achieved mastery learning.
\end{abstract}

Keywords: Implementation, Scramble Model, Powerpoint, Learning Outcomes

\begin{abstract}
Abstrak: Penelitian ini bertujuan untuk mengetahui penerapan model pembelajaran scramble berbasis powerpoint dalam meningkatkan hasil belajar siswa pada bidang studi Sejarah Kebudayaan Islam Kelas VII Satu di Madrasah Tsanawiyah PP. Nurul Islam Kampung Baru. Penelitian ini merupakan penelitian tindakan kelas, yaitu suatu penelitian yang bersifat praktis, situasional dan konteksual berdasarkan permasalahan yang muncul dalam kegiatan pembelajaran bidang studi Sejarah Kebudayaan Islam di Madrasah Tsanawiyah PP. Nurul Islam Kampung Baru. Berdasarkan penelitian yang dilakukan dapat disimpulkan bahwa pelaksanaan pembelajaran Sejarah Kebudayaan Islam dengan menerapkan model pembelajaran scramble berbasis powerpoint dilaksanakan dengan langkah-langkah yaitu: pra pembelajaran, kegiatan awal, kegiatan inti, dan penutup. Setelah menerapkan model pembelajaran scramble berbasis powerpoint di kelas VII Satu di Madrasah Tsanawiyah PP. Nurul Islam Kampung Baru menunjukkan ada peningkatan hasil belajar siswa. Hal ini terlihat dari, sebelum tindakan rata-rata kelas baru mencapai 71,30 dan hanya 9 orang siswa atau 39,13\% yang mencapai ketuntasan belajar, namun pada siklus I, dengan menggunakan model pembelajaran scramble berbasis power point mengalami peningkatan dengan rata-rata kelas mencapai 76,39 dan terdapat 15 orang siswa atau $65,22 \%$ yang mencapai ketuntasan belajar, dan peningkatan tersebut berlanjut pada siklus II dengan rata-rata kelas mencapai 85,74 dan 22 orang siswa atau 95,65\% yang mencapai ketuntasan belajar.
\end{abstract}

Kata Kunci : Penerapan, Model Scramble, Power Point, Hasil Belajar 


\section{PENDAHULUAN}

Pendidikan di Indonesia memiliki peran penting dalam mengembangkan potensi individu. Hal tersebut sesuai dengan konteks pendidikan nasional Indonesia yang ditegaskan dalam pasal 1 UU No 20 tahun 2003 tentang Sistem Pendidikan Nasional, ditegaskan bahwa pendidikan adalah usaha sadar dan terencana untuk mewujudkan suasana belajar dan proses pembelajaran agar peserta didik secara aktif mengembangkan potensi dirinya untuk memiliki kekuatan spiritual keagamaan, pengendalian diri, kepribadian, kecerdasan, akhlak mulia, serta keterampilan yang diperlukan dirinya, masyarakat, bangsa dan Negara (Wina Putra \& Udin, 2011: 2\&5). Berdasarkan konteks tersebut, pendidikan tidak hanya berkenaan dengan aspek kognitif, tetapi melingkupi segala potensi individu termasuk nilai, sikap dan keterampilan psikomotorik. (Rifa'i, Achmad dan Catharina Tri Anni, 2015: 89)

Di sekolah atau lembaga pendidikan yang berwawasan Islam, salah satu bidang studi yang diajarkan adalah Sejarah Kebudayaan Islam (SKI). Bidang studi SKI merupakan bidang studi yang materinya berisikan peristiwa sejarah masa lalu, sehingga di sekolah guru sering terjebak menggunakan metode pengajaran yang lebih mengarah kepada metode ceramah atau bercerita saja. Padahal kedua metode tersebut dapat mendatangkan kebosanan siswa jika guru tidak dapat menyesuaikan dengan kondisi atau keadaan siswa. Selain itu metode tersebut membuat siswa kurang kreatif dalam menggunakan semua aspek kecerdasannya. (Sugandi, Achmad, 2005: 32)

Begitu pula halnya yang terjadi di Madrasah Tsanawiyah PP. Nurul Islam Kampung Baru. Berdasarkan kegiatan observasi awal dalam pembelajaran SKI ditemukan permasalahan seperti metode pembelajaran yang digunakan adalah metode ceramah, sehingga siswa kurang kreatif dalam menggunakan semua aspek kecerdasannya, kegiatan pembelajaran hanya berlangsung satu arah, sehingga siswa terlihat pasif hanya memperhatikan guru saja, siswa terlihat bosan dan jenuh selama mengikuti proses pembelajaran, Guru cenderung menguasai kelas sehingga siswa enggan untuk bertanya dan kurang leluasa untuk menyampaikan ide-idenya, Siswa takut bertanya kepada guru apabila belum memahami materi, dan Guru tidak menggunakan media pembelajaran yang tepat.

Dari permasalahan di atas, menyebabkan hasil belajar siswa menjadi rendah yang disebabkan kurangnya keaktifan siswa dalam belajar, padahal keterlibatan aktif siswa akan mendorong siswa untuk lebih mengerti apa yang mereka lakukan sehingga memberikan pemahaman yang lebih baik (Siddiq, M. Djauhar, dkk., 2007 : 67). Jika belajar dilakukan secara aktif maka siswa akan terdorong untuk mencari sesuatu. Mereka akan mencari jawaban atas pertanyaan, mencari informasi untuk memecahkan masalahnya atau mencari cara untuk menyelesaikan tugasnya (Mel Silberman, 2005: 5), yang berdampak kepada hasil belajar siswa.

Untuk itu, peneliti menetapkan solusi alternatif untuk memecahkan masalah tersebut, yaitu melalui model pembelajaran scramble yang dipadukan dengan penggunaan media power point. Menurut Robert B. Taylor sebagaimana yang dikutip oleh Miftahul Huda, scramble merupakan salah satu metode pembelajaran yang dapat meningkatkan konsentrasi dan kecepatan berpikir siswa (Miftahul Huda, 2014: 303). Selanjutnya Suhani menjelaskan bahwa model pembelajaran scramble bersifat aktif. Siswa dituntut aktif bekerjasama menyelesaikan kartu soal untuk memperoleh point bagi kelompok mereka. Siswa mempunyai tanggung jawab masingmasing dalam menyelesaikan tugasnya. (Edi Kurniawan dan Rahmiza Dewi, 2019). Setiap kelompok bekerjasama diharapkan dapat meningkatkan kebersamaan (Agus Suhani, Implementasi Model Pembelajaran Scramble, 2017). Model pembelajaran scramble diharapkan mampu mengatasi permasalahan pembelajaran SKI sehingga dapat meningkatkan kualitas pembelajaran SKI di Madrasah Tsanawiyah PP. Nurul Islam Kampung Baru.

Metode penelitian yang digunakan dalam penelitian ini adalah penelitian tindakan kelas (PTK) yang terdiri dari 2 siklus dilakukan dalam 2 kali pertemuan. Lokasi penelitian ini adalah di Madrasah Tsanawiyah PP. Nurul Islam yang terletak di desa Kampung Baru Kecamatan Gunung Toar Kabupaten Kuantan Singingi Propinsi Riau. Waktu penelitian dilakukan selama 3 bulan, terhitung dari bulan Agustus sampai dengan Bulan Oktober 2017.

Subjek penelitian ini adalah guru SKI dan siswa kelas VII Satu di Madrasah Tsanawiyah PP. Nurul Islam Kampung Baru Kabupaten Kuantan Singingi. Sedangkan yang menjadi objek penelitian ini adalah penerapan model pembelajaran Scramble Berbasis Powerpoint untuk meningkatkan 
hasil belajar siswa pada bidang studi Sejarah Kebudayaan Islam di Madrasah Tsanawiyah PP. Nurul Islam Kampung Baru.

Populasi penelitian ini adalah guru mata pelajaran SKI dan siswa Madrasah Tsanawiyah PP. Nurul Islam Kampung Baru yang berjumlah 1 orang guru SKI dan 23 siswa kelas VII Satu. Pengambilan sampel menggunakan metode stratified proportional random sampling yaitu teknik pengambilan sampel yang menggunakan gabungan dari 3 teknik, berstrata, proporsi dan acak (Suharsimi Arikunto, 2006:117) Sehingga penulis memutuskan untuk mengambil kelas VII Satu pada Madrasah Tsanawiyah PP. Nurul Islam Kampung Baru sebagai sampel dengan jumlah siswa sebanyak 23 orang.

Pengumpulan data melalui observasi dilakukan sendiri oleh peneliti dibantu oleh guru bidang studi SKI di Madrasah Tsanawiyah PP. Nurul Islam Kampung Baru. Observasi dilakukan pada kelas yang dijadikan subyek penelitian untuk mendapatkan gambaran secara langsung kegiatan belajar anak di kelas. Observasi yang dilakukan meliputi proses pembelajaran guru dan anak dengan menggunakan Model Pembelajaran Scramble Berbasis Powerpoint. Metode observasi ini merupakan teknik pengumpulan data yang digunakan dengan cara pengamatan dan pencatatan secara sistematis terhadap gejala yang tampak pada objek penelitian (S. Margono, 1997:158)

Wawancara adalah sebuah dialog yang dilakukan oleh peneliti untuk memperoleh informasi dari terwawancara. (Azhar Arsyad, 2013 : 32). Sedangkan yang penulis wawancarai adalah Guru SKI dan siswa, serta responden lainnya yang terkait dengan penelitian ini.

Dokumentasi yaitu mencari data mengenai hal-hal atau variabel yang terdapat dalam catatan, transkrip, buku, surat kabar, majalah, notulen dan sebagainya (Suharsimi Arikunto, 2006:231). Jadi, peneliti mencari data yang diperlukan sebagai penunjang kevalidan akan penelitian seperti dokumen-dokumen tentang profil Madrasah Tsanawiyah PP. Nurul Islam Kampung Baru.

\section{HASIL DAN PEMBAHASAN}

Berdasarkan penyajian data tentang Penerapan Model pembelajaran scramble pada bidang studi Sejarah Kebudayaan Islam di MTs. PP. Nurul Islam Kampung Baru Kecamatan Gunung Toar yang dilakukan dalam bentuk penelitian tindakan kelas yang dilaksanakan pada setiap hari Sabtu jam ke-1 dan 2 pada kelas VII Satu, yang dilakukan sebanyak 3 siklus. Maka dapat dilakukan analisa data dengan hasil sebagai berikut.

Penerapan model pembelajaran scramble pada siklus I dan siklus II telah dilaksanakan dengan sangat baik, hal ini dapat dilihat melalui rekapitulasi hasil observasi sebagai berikut.

Dari rekapitulasi Tabel 1. pada tahap Pra Siklus penerapan model pembelajaran scramble baru mencapai $30 \%$ dari aspek yang diamati. Selanjutnya pada Siklus I penerapan model pembelajaran scramble sudah mencapai $90 \%$, dan pada Siklus II penerapannya meningkat menjadi $100 \%$.

Tabel 1. Rekapitulasi Hasil Observasi Pemodelan Model Scramble

\begin{tabular}{|c|c|c|c|c|c|c|c|}
\hline \multirow{3}{*}{ No } & \multirow{3}{*}{ Indikator / Aspek Yang Diamati } & \multicolumn{6}{|c|}{ Hasil Pengamatan } \\
\hline & & \multicolumn{2}{|c|}{ Pra Siklus } & \multicolumn{2}{|c|}{ Siklus I } & \multicolumn{2}{|c|}{ Siklus II } \\
\hline & & Ya & Tidak & Ya & Tidak & Ya & Tidak \\
\hline 1 & Menyampaikan tujuan pembelajaran & & $\sqrt{ }$ & $\sqrt{ }$ & & $\sqrt{ }$ & \\
\hline 2 & Apersepsi & $\sqrt{ }$ & & $\sqrt{ }$ & & $\overline{\sqrt{ }}$ & \\
\hline 3 & Memotivasi siswa & $\sqrt{ }$ & & & $\sqrt{ }$ & $\sqrt{ }$ & \\
\hline 4 & $\begin{array}{l}\text { Pemodelan Pembelajaran Scramble Berbasis } \\
\text { Powerpoint }\end{array}$ & & & & & & \\
\hline & $\begin{array}{l}\text { a. Menyiapkan kartu soal, kartu jawaban } \\
\text { dan powerpoint untuk proses } \\
\text { pembelajaran } \\
\end{array}$ & & $\sqrt{ }$ & $\sqrt{ }$ & & $\sqrt{ }$ & \\
\hline & $\begin{array}{l}\text { b. Menyajikan materi menggunakan media } \\
\text { powerpoint }\end{array}$ & & $\sqrt{ }$ & $\sqrt{ }$ & & $\sqrt{ }$ & \\
\hline & $\begin{array}{lll}\text { c. } \text { Membentuk } & \text { kelompok } & \text { untuk }\end{array}$ & & $\sqrt{ }$ & $\sqrt{ }$ & & $\overline{\sqrt{ }}$ & \\
\hline
\end{tabular}




\begin{tabular}{|c|c|c|c|c|c|c|c|}
\hline & mendiskusikan soal-soal yang tersedia & & & & & & \\
\hline & $\begin{array}{l}\text { d. Membagikan kartu soal dan kartu } \\
\text { jawaban pada masing-masing kelompok }\end{array}$ & & $\sqrt{ }$ & $\sqrt{ }$ & & $\sqrt{ }$ & \\
\hline & $\begin{array}{l}\text { e. Siswa berkelompok mendiskusikan } \\
\text { kartu soal dan mencari jawaban untuk } \\
\text { setiap soal dalam kartu soal }\end{array}$ & & $\sqrt{ }$ & $\sqrt{ }$ & & $\sqrt{ }$ & \\
\hline & $\begin{array}{llll}\text { f. } & \begin{array}{l}\text { Memberikan } \\
\text { kelompok }\end{array} & \text { penilaian } & \text { hasil kerja } \\
\end{array}$ & & $\sqrt{ }$ & $\sqrt{ }$ & & $\sqrt{ }$ & \\
\hline 5 & $\begin{array}{l}\text { Merangkum pelajaran dan Menutup kegiatan } \\
\text { pembelajaran }\end{array}$ & $\sqrt{ }$ & & $\sqrt{ }$ & & $\sqrt{ }$ & \\
\hline & Jumlah & 3 & 7 & 9 & 1 & 10 & \\
\hline & Persentase & $30 \%$ & $70 \%$ & $90 \%$ & $10 \%$ & $100 \%$ & 0\% \\
\hline
\end{tabular}

\section{Sumber : Data Olahan Observasi}

Penerapan model pembelajaran scramble memberikan pengaruh yang signifikan terhadap hasil belajar siswa, yang dapat dilihat pada tabel berikut.

Tabel 2. Rekapitulasi Hasil Belajar Siswa

\begin{tabular}{|c|c|c|c|c|c|c|}
\hline \multirow{2}{*}{ No Urut Siswa } & \multicolumn{2}{|c|}{ Pra Siklus } & \multicolumn{2}{|c|}{ Siklus I } & \multicolumn{2}{|c|}{ Siklus II } \\
\hline & Nilai & Ket & Nilai & Ket & Nilai & Ket \\
\hline 1 & 70 & TT & 76 & $\mathrm{~T}$ & 85 & $\mathrm{~T}$ \\
\hline 2 & 67 & TT & 74 & TT & 82 & $\mathrm{~T}$ \\
\hline 3 & 70 & TT & 80 & $\mathrm{~T}$ & 85 & $\mathrm{~T}$ \\
\hline 4 & 68 & TT & 72 & TT & 83 & $\mathrm{~T}$ \\
\hline 5 & 76 & $\mathrm{~T}$ & 80 & $\mathrm{~T}$ & 91 & $\mathrm{~T}$ \\
\hline 6 & 75 & $\mathrm{~T}$ & 78 & $\mathrm{~T}$ & 90 & $\mathrm{~T}$ \\
\hline 7 & 75 & $\mathrm{~T}$ & 78 & $\mathrm{~T}$ & 88 & $\mathrm{~T}$ \\
\hline 8 & 65 & TT & 73 & TT & 75 & $\mathrm{~T}$ \\
\hline 9 & 75 & $\mathrm{~T}$ & 80 & $\mathrm{~T}$ & 90 & $\mathrm{~T}$ \\
\hline 10 & 71 & TT & 76 & $\overline{\mathrm{T}}$ & 86 & $\mathrm{~T}$ \\
\hline 11 & 77 & $\mathrm{~T}$ & 80 & $\mathrm{~T}$ & 92 & $\mathrm{~T}$ \\
\hline 12 & 69 & TT & 74 & TT & 84 & $\mathrm{~T}$ \\
\hline 13 & 75 & $\mathrm{~T}$ & 82 & $\mathrm{~T}$ & 90 & $\mathrm{~T}$ \\
\hline 14 & 69 & TT & 75 & $\mathrm{~T}$ & 84 & $\mathrm{~T}$ \\
\hline 15 & 67 & TT & 73 & TT & 82 & $\mathrm{~T}$ \\
\hline 16 & 69 & TT & 76 & $\mathrm{~T}$ & 84 & $\mathrm{~T}$ \\
\hline 17 & 70 & TT & 76 & $\mathrm{~T}$ & 85 & $\mathrm{~T}$ \\
\hline 18 & 68 & TT & 74 & TT & 83 & $\mathrm{~T}$ \\
\hline 19 & 79 & $\mathrm{~T}$ & 78 & $\mathrm{~T}$ & 94 & $\mathrm{~T}$ \\
\hline 20 & 75 & $\mathrm{~T}$ & 76 & $\mathrm{~T}$ & 90 & $\mathrm{~T}$ \\
\hline 21 & 75 & $\mathrm{~T}$ & 80 & $\mathrm{~T}$ & 90 & $\mathrm{~T}$ \\
\hline 22 & 70 & TT & 74 & TT & 85 & $\mathrm{~T}$ \\
\hline 23 & 65 & TT & 72 & TT & 74 & TT \\
\hline Jumlah Nilai & 1640 & & 1757 & & 1972 & \\
\hline Rata-rata Kelas & 71,30 & & 76,39 & & 85,74 & \\
\hline $\begin{array}{l}\text { Ketuntasan } \\
\text { Belajar }\end{array}$ & 9 & & 15 & & 22 & \\
\hline \% Ketuntasan & 39,13 & & 65,22 & & 95,65 & \\
\hline
\end{tabular}

Sumber : Data Olahan Penelitan 
Berdasarkan rekapitulasi hasil penelitian pada tabel 4.12 di atas, dapat dijelaskan bahwa sebelum tindakan (pra siklus) rata-rata kelas baru mencapai 71,70. Dan pada siklus I, pembelajaran Sejarah Kebudayaan Islam dengan menggunakan model pembelajaran scramble mengalami peningkatan dengan rata-rata kelas mencapai 76,39 , dan peningkatan tersebut berlanjut pada siklus II dengan rata-rata kelas mencapai 85,74. Peningkatan rata-rata kelas hasil belajar siswa secara jelas dapat dilihat pada grafik berikut ini.

Gambar 1. Grafik Rata-rata Kelas Hasil Belajar Siswa

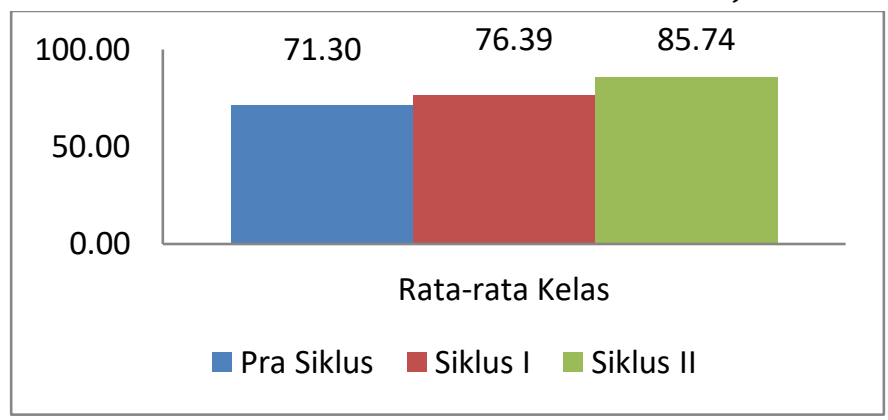

Kemudian dari rekapitulasi hasil penelitian pada tabel 4.12 di atas, dapat juga dijelaskan bahwa sebelum tindakan (pra siklus) pada bidang studi Sejarah Kebudayaan Islam hanya 9 orang siswa atau 39,13\% yang mencapai ketuntasan belajar atau yang telah memenuhi standar kriteria ketuntasan minimal (KKM) yang ditentukan oleh guru bidang studi yaitu sebesar 75. Pada siklus I, dengan menggunakan model pembelajaran scramble mengalami peningkatan yaitu terdapat 15 orang siswa atau $65,22 \%$ yang mencapai ketuntasan belajar atau yang telah memenuhi standar kriteria ketuntasan minimal (KKM). Peningkatan tersebut berlanjut pada siklus II dengan 22 orang siswa atau 95,65\% yang telah memenuhi standar kriteria ketuntasan minimal (KKM).

Gambar 2. Grafik Ketuntasan Belajar Siswa
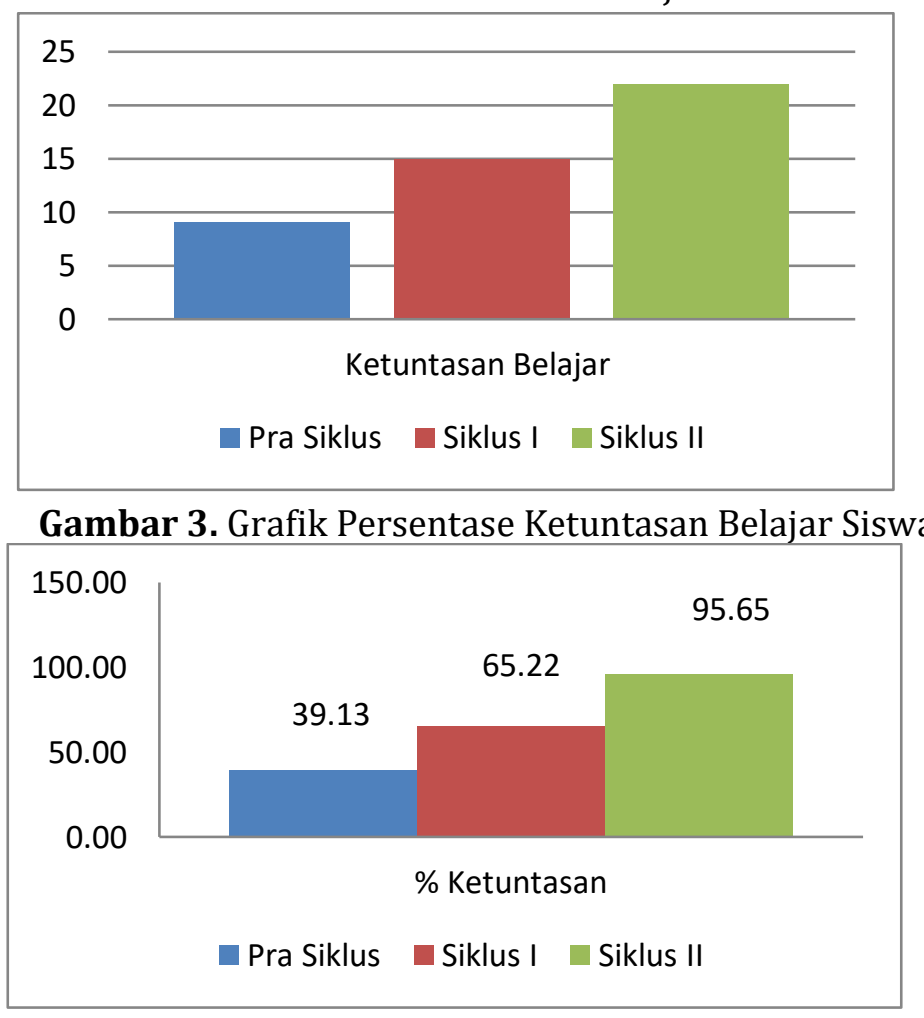

Dengan hasil tersebut di atas, menunjukkan bahwa penerapan model pembelajaran scramble dapat meningkatkan hasil belajar siswa pada bidang studi Sejarah Kebudayaan Islam di MTs. PP. Nurul Islam Kampung Baru Kecamatan Gunung Toar. 


\section{KESIMPULAN}

Pelaksanaan pembelajaran Sejarah Kebudayaan Islam dengan menerapkan model pembelajaran scramble berbasis powerpoint dilaksanakan dengan langkah-langkah yaitu Pra Pembelajaran, Kegiatan Awal, Kegiatan Inti, dan Penutup.

Setelah pelaksanaan pembelajaran Sejarah Kebudayaan Islam dengan menerapkan model pembelajaran scramble berbasis powerpoint di Kelas VII Satu di Madrasah Tsanawiyah PP. Nurul Islam Kampung Baru menunjukkan bahwa ada peningkatan hasil belajar siswa. Hal ini terlihat dari, sebelum tindakan (pra siklus) rata-rata kelas baru mencapai 71,30 dan hanya 9 orang siswa atau 39,13\% yang mencapai ketuntasan belajar, namun pada siklus I, dengan menggunakan model pembelajaran scramble berbasis power point mengalami peningkatan yaitu dengan rata-rata kelas mencapai 76,39 dan terdapat 15 orang siswa atau 65,22\% yang mencapai ketuntasan belajar, dan peningkatan tersebut berlanjut pada siklus II dengan rata-rata kelas mencapai 85,74 dan 22 orang siswa atau 95,65\% yang mencapai ketuntasan belajar.

\section{DAFTAR PUSTAKA}

Agus Suhani. (2010) Implementasi Model Pembelajaran Scramble. http://agussambeng. blogspot.com/2010/10/implementasi-model- pembelajaran.html.

Arikunto, Suharsimi. (2006). Prosedur Penelitian Suatu Pendekatan Praktek. Jakarta: Rineka Cipta.

Azhar Arsyad. (2013). Media Pembelajaran. Jakarta: Rajawali Press.

Kurniawan, Edi, Dewi, Rahmiza, (2019). Penerapan Model Pembelajaran Aktif Tipe Group To Groep Exchange (GGE) dalam Meningkatkan Hasil Belajar Siswa pada Materi Hidrokarbon Kelas X SMA Negeri 10 Pekanbaru. JEDCHEM (Journal Education and Chemistry). Vol 1 No 1 (2019). http://ejournal.uniks.ac.id/index.php/JEDCHEM/article/view/73/46

Mel Silberman. (2005). Active Learning: 101 Strategi Pembelajaran Aktif. penerjemah: Sarjuli et.al., Yogyakarta: Yappendis.

Miftahul Huda. (2014). Model-model Pengajaran dan Pembelajaran, (Yogyakarta: Pustaka Pelajar.

Rifa'i, Achmad dan Catharina Tri Anni. (2015). Psikologi Pendidikan, Semarang: Universitas Negeri Semarang Press.

Robert B. Taylor. (1992). Analisis Data Kualitatif, Jakarta: PT. UI Press.

S. Margono. (1997). Metodologi Penelitian Pendidikan, Jakarta: Rineka Cipta.

Siddiq, M. Djauhar, dkk. (2007). Pengembangan Bahan Pelajaran SD. Jakarta : Dirjen Dikti Depdiknas.

Sugandi, Achmad. (2005). Teori Pembelajaran. Semarang: UNNES Press.

Wina Putra dan Udin. (2011). Cooperative Learning Teori \& Aplikasi PAIKEM. Yogyakarta: Pustaka Pelajar. 